\title{
Ain't She a Woman? How Warmth and Competence Stereotypes about Women and Female Politicians Contribute to the Warmth and Competence Traits Ascribed to Individual Female Politicians
}

\author{
Elizabeth R. Brown ${ }^{\dagger}$,* Curtis E. Phills ${ }^{\dagger}$, Dominic G. Mercurio IV, \\ Matthew Olah, and Candice J. Veilleux \\ University of North Florida
}

Hillary Clinton was the first woman nominated for President by a major political party in the United States. Like most women in politics, she faced negative evaluations, in part, due to the inconsistency between the traits typically associated with leaders (competence) versus women (warmth). Because understanding the categorization of an individual female politician is essential to the development of successful bias interventions, we examined the extent to which Hillary Clinton and a novel female politician were categorized as women versus female politicians. In three studies we investigated how the warmth and competence stereotypes associated with women and female politicians contributed to the warmth and competence traits associated with Hillary Clinton and a novel female political candidate. Consistent with a subtyping account, the warmth and competence stereotypes associated with female politicians, but not women, predicted Hillary Clinton's warmth and competence traits (Studies 1-3). However, consistent with a subgrouping account, the warmth and competence stereotypes associated with both women and female politicians predicted a novel female politician's warmth and competence traits (Study 3). Implications for bias reduction interventions are discussed.

${ }^{*}$ Correspondence concerning this article should be addressed to Elizabeth R. Brown, University of North Florida, Psychology, 1 UNF Drive, Building 51, Room 3413 Jacksonville, FL, United States, 32224 [e-mail: elizabeth.r.brown@unf.edu].

${ }^{\dagger}$ Elizabeth Brown and Curtis Phills are sharing first authorship of this manuscript.

105 


\begin{abstract}
That man over there says that women need to be helped into carriages, and lifted over ditches, and to have the best place everywhere. Nobody ever helps me into carriages, or over mud-puddles, or gives me any best place! And ain't I a woman? Look at me! Look at my arm! I have ploughed and planted, and gathered into barns, and no man could head me! And ain't I a woman? I could work as much and eat as much as a man -when I could get it-and bear the lash as well! And ain't I a woman? I have borne thirteen children, and seen most all sold off to slavery, and when I cried out with my mother's grief, none but Jesus heard me! And ain't I a woman?
\end{abstract}

-Sojourner Truth, Women's Convention, Akron, Ohio, 1851

In 2016, Hillary Clinton became the first woman nominated for President by a major political party in the United States and, as such, filled a role that had been exclusively held by men for centuries. Like all female politicians, Hillary Clinton faced challenges, including negative evaluations, partially stemming from leadership being associated more with men than women (Eagly \& Karau, 2002). Though these challenges may contribute to the underrepresentation of women in political office (Dolan, 2010; Huddy \& Terkildsen, 1993), because Hillary Clinton was running to become the nation's President-the top leadership position in the country-contrasts between the traits traditionally associated with women (i.e., warmth) and the traits traditionally associated with leadership (i.e., competence) may have been especially pronounced in voters' minds. Just as Sojourner Truth responded to claims that she was not a woman because her strength and abilities were equal or better than that of any man, it may be the case that people did not think of Hillary Clinton as a woman because of her abilities and success as a political candidate. Because categorizing Hillary Clinton in a way that excludes her group membership as a woman might inhibit stereotype change (Richards \& Hewstone, 2001) and the effectiveness of anti-bias interventions that target women's representation in leadership (see Dasgupta \& Asgari, 2004 for an example intervention), it is critical to understand the extent to which Hillary Clinton and other female politicians are categorized as women. The current research examines how the stereotypes associated with women and female politicians contribute to the traits ascribed to female political candidates like Hillary Clinton.

\title{
Stereotypes and Categorization Processes
}

Stereotypes are beliefs about the attributes associated with a social group (Dovidio, Brigham, Johnson, \& Gaertner, 1996); when a person is categorized as a group member, the group's stereotypes are applied to that person (Fiske \& Neuberg, 1990). Stereotypic traits can be classified into two fundamental categories (Fiske, Cuddy, Glick, \& Xu, 2002): warmth (an other-orientation) and competence (a self-orientation; Cuddy, Fiske, \& Glick, 2008; Fiske et al., 2002). Warmth, and its related constructs of communion (e.g., Eagly, Wood, \& Diekman, 2000) and relatedness (e.g., Ryan \& Deci, 2000), includes traits such as honest, faithful, and courteous. In contrast, competence, and its related constructs of agency 
(e.g., Eagly et al., 2000) and autonomy (e.g., Ryan \& Deci, 2000), includes traits such as independent, industrious, and intelligent. Women are rated high on warmth and low on competence stereotypes (e.g., Eagly \& Karau, 2002; Fiske et al., 2002), whereas female leaders (e.g., Eagly \& Karau, 2002; Koenig et al., 2011) are rated high on competence and low on warmth stereotypes. These traits (i.e., warmth and competence) are quickly applied to individuals categorized as members of their associated social categories (i.e., woman, female politician; e.g., Allport, 1954; Fiske \& Neuberg, 1990; Stangor, Lynch, Duan, \& Glass, 1992; Tajfel, 1981). As such, voter's evaluations of political candidates reflect warmth and competence evaluations (Abelson, Kinder, Peters, \& Fiske, 1982; Wojciszke \& Klusek, 1996).

Because an individual female politician is both a woman and a female politician, it is important to examine whether the traits applied to her result from a subtyping categorization process (she is categorized as a female politician but not as a woman; Richards \& Hewstone, 2001) or a subgrouping categorization process (she is categorized as both a woman and a female politician; Richards \& Hewstone, 2001). If categorization of an individual female politician is driven by subtyping, how participants stereotype women should not be related to the traits they ascribe to a female politician. However, if categorization of an individual female politician is driven by subgrouping, how participants stereotype women and female politicians should both be related to the traits they ascribe to a female politician. Notably, categorization of an individual female politician may still be driven by a subtyping process (i.e., they are not categorized as women) even if she is rated highly on traits traditionally associated with women like warmth because multiple categorization processes could result in a specific trait being associated with a group (De Houwer \& Moors, 2015). In this case, a female politician could be rated high on warmth, not because she is categorized as a woman (subgrouping), but because female political candidates are rated warmer than their male political candidate counterparts (Huddy \& Terkildsen, 1993).

\section{Investigating Categorization Processes}

A number of different methodological techniques have been used to investigate subtyping and subgrouping categorization processes. For instance, subtyping has been examined by investigating the extent to which a compound group (e.g., female politicians) was associated with the typicality of the traits of its component groups (e.g., women or female politicians; e.g., Johnston \& Hewstone, 1992; Kunda \& Oleson, 1995) whereas subgrouping has been examined by investigating the percentage of individuals within a compound group that possessed traits typical of its component groups (e.g., Park \& Judd, 1990; Park, Ryan, \& Judd, 1992). Furthermore, both subtyping and subgrouping have been examined by instructing participants to sort or list traits associated with a compound group as well as its 
related component groups (e.g., Hewstone, Macrae, Griffiths, Milne, \& Brown, 1994; Johnston \& Hewstone, 1992; Park et al., 1992; Maurer, Park, \& Rothbart, 1995; Schneider \& Bos, 2011; 2014).

In one such listing study, researchers investigated whether the stereotypes associated with female politicians were similar or different than the stereotypes associated with women (Schneider \& Bos, 2014). Participants were provided with a list of stereotypes and asked to identify which stereotypes applied to various social categories including women and female politicians; the percentage of participants who selected a particular stereotype were then compared across the social categories. The top five stereotypes associated with women were warmth-related, and the top five stereotypes associated with female politicians were competence-related (Schneider \& Bos, 2014), consistent with the idea that women are associated with warmth and politicians are associated with competence (e.g., Eagly \& Karau, 2002). Lending further credence to the subtyping hypothesis, the stereotypes of women (i.e., feminine, compassionate) were not the same as the stereotypes of female politicians (i.e., confident, assertive). In fact, 18 stereotypes were ascribed to women but not to female politicians (Schneider \& Bos, 2014).

\section{Moving Beyond the Outcomes of Categorization Processes}

Although Schneider and Bos' (2014) findings are consistent with the subtyping hypothesis, because they focus on the outcomes of categorization processes (i.e., the traits associated with groups) and those outcomes could be the result of multiple categorization processes, it is unclear how compound groups are categorized. The current research moves beyond examining whether the stereotypes of female politicians are similar or different than the stereotypes of women (the outcome of categorization processes) by being one of the first to examine categorization processes directly. We assessed how the warmth and competence stereotypes associated with women and female politicians are related to the warmth and competence traits ascribed to individual female politicians like Hillary Clinton. For example, stereotyping of an individual female politician as competent could be driven by subgrouping categorization processes if her competence ratings are related to stereotyping of women and female politicians. Alternatively, they could be driven by subtyping categorization processes if her competence ratings are only related to stereotyping of female politicians. This is true regardless of the extent to which she is rated as competent.

Since evaluations of individuals may be contextualized (Gawronski, Rydell, Vervliet, \& De Houwer, 2010), we also examined how categorization processes may be influenced by contextual cues. Recent research has shown that the context in which a trait is associated with a person influences how strong that trait is associated with the person (Huang, Sacchi, \& Sherman, 2017). Thus, we explored whether presenting an individual female politician in a political context inhibited 
categorizing her as a woman (subtyping) because of the salience of the political cues. We also examined whether presenting an individual female politician in a family context facilitated categorizing her as a woman (subgrouping) because of the salience of familial cues.

\section{Study Overview and Exploratory Hypotheses}

Three experiments used novel methodological and analytical strategies to examine categorization processes directly by investigating whether specific female politicians were categorized as women, female politicians, or both. Studies 1 and 2 focused on Hillary Clinton because of her historic achievement and the importance of understanding how she was categorized. Study 3 examined how warmth and competence traits were applied to Hillary Clinton and a novel female politician to investigate whether categorization processes differ for novel female politicians. Using regression analyses, we examined whether the warmth and competence stereotypes associated with women and female politicians predicted the warmth and competence traits applied to specific female politicians, Hillary Clinton (Studies 1-3), and a novel female politician (Study 3). Using these procedures we disentangled whether the relatively higher competence and lower warmth ratings of a specific female politician were the results of subtyping (predicted by stereotyping of female politicians only) or subgrouping (predicted by stereotyping of both women and female politicians). We also examined how contextualization might moderate categorization to disentangle whether categorization might be influenced by political or familial contextual cues. Given the exploratory nature of the current work, we investigated whether subtyping, subgrouping, or contextualization occurred. The following were our exploratory hypotheses.

Subtyping hypothesis. The warmth/competence stereotypes associated with female politicians but not the warmth/competence stereotypes associated with women would predict the warmth/competence traits ascribed to an individual female politician.

Subgrouping hypothesis. The warmth/competence stereotypes associated with female politicians and women would predict the warmth/competence traits ascribed to an individual female politician.

Contextualization hypotheses. In a political context, the warmth/competence stereotypes associated with female politicians would predict the warmth/ competence traits ascribed to an individual female politician (subtyping), because the category female politician would be salient. In a family context, the warmth/ competence stereotypes associated with women and female politicians would 
predict the warmth/competence traits ascribed to an individual female politician (subgrouping), because the category women would be salient.

\section{Studies 1 and 2}

Because Studies 1-2 utilized the same survey procedures, we combined the presentation of the method and the results of these studies.

\section{Method}

Participants. In Study 1, 241 college students (80.5\% women, 0.8\% did not identify a gender; $66.39 \%$ White, 5.39\% Latino, 9.13\% Black, 7.88\% Asian, $6.22 \%$ other, $4.98 \%$ did not identify; ages $18-56$, median age $=21 ; 35.7 \%$ liberal, $34.4 \%$ moderate, $26.9 \%$ conservative) at a mid-sized, southeastern university were recruited in exchange for partial course credit.

In Study 2, 487 participants (49.9\% women, $16.6 \%$ did not identify a gender; 64.07\% White, $2.46 \%$ Latino, $8.01 \%$ Black, $4.31 \%$ Asian, $3.90 \%$ other, $17.25 \%$ did not identify; ages $18-79$, median age $=34 ; 41.7 \%$ liberal, $19.7 \%$ moderate, $22.1 \%$ conservative) were recruited using Amazon's Mechanical TURK system (MTURK) in exchange for payment.

Procedure. Participants viewed a picture of Hillary Rodham Clinton (HRC; context manipulation) and then completed ratings of the warmth and competence of the following groups/individuals in the order provided: women, female politicians, and Hillary Clinton. Demographic information was also collected.

Context manipulation. Participants were told we were interested in their "thoughts about candidates running for political office" and to "take some time and look at the candidate pictured below." Participants were then randomly assigned to view a picture of Hillary Clinton either in no context, in a political context, or in a family context (see Appendix A).

Warmth and competence ratings. Next participants rated women's, female politicians', and HRC's warmth (8 items per group/individual rated) and competence (eight items per group/individual rated; Fiske et al., 2002) using 5-point scales ranging from 1 (Not at all) to 5 (Extremely). Warmth and competence items were interspersed throughout the group ratings. Example competence items included "As viewed by society, how competent are/is women/female politicians/HRC?" and "As viewed by society, how intelligent are/is women/female politicians/HRC?"; example warmth items included "As viewed by society, how warm are/is women/female politicians/HRC?" and "As viewed by society, how 
Table 1. Means, Standard Deviations, and Ranges for All Measures in Studies 1-3

\begin{tabular}{|c|c|c|c|c|c|c|c|c|c|}
\hline & \multicolumn{3}{|c|}{ Study 1} & \multicolumn{3}{|c|}{ Study 2} & \multicolumn{3}{|c|}{ Study 3} \\
\hline & $M$ & $S D$ & Range & $M$ & $S D$ & Range & $M$ & $S D$ & Range \\
\hline Women's perceived warmth & 3.48 & 0.46 & $2-5$ & 3.47 & 0.54 & $1-5$ & 3.59 & .52 & $1.5-5$ \\
\hline Women's perceived competence & 3.08 & 0.63 & $1.63-5$ & 3.21 & 0.66 & $1.5-5$ & 3.29 & .70 & $1.25-5$ \\
\hline $\begin{array}{l}\text { Female politicians' perceived } \\
\text { warmth }\end{array}$ & 2.88 & 0.60 & $1-4.63$ & 2.85 & 0.67 & $1-5$ & 3.10 & .72 & $1-5$ \\
\hline $\begin{array}{l}\text { Female politicians' perceived } \\
\text { competence }\end{array}$ & 2.98 & 0.68 & $1-5$ & 3.14 & 0.75 & $1-5$ & 3.37 & .75 & $1-5$ \\
\hline $\begin{array}{l}\text { Hillary Clinton's perceived } \\
\text { warmth }\end{array}$ & 2.64 & 0.65 & $1-4.63$ & 2.42 & 0.82 & $1-5$ & 2.44 & .81 & $1-4.88$ \\
\hline $\begin{array}{l}\text { Hillary Clinton's perceived } \\
\text { competence }\end{array}$ & 3.09 & 0.70 & $1-5$ & 3.27 & 0.87 & $1-5$ & 3.37 & .86 & $1-5$ \\
\hline $\begin{array}{l}\text { Karen Johnson's perceived } \\
\text { warmth }\end{array}$ & - & - & - & - & - & - & 3.40 & .63 & $1.38-5$ \\
\hline $\begin{array}{l}\text { Karen Johnson's perceived } \\
\text { competence }\end{array}$ & - & - & - & - & - & - & 3.59 & .61 & $1.5-5$ \\
\hline
\end{tabular}

sensitive are/is women/female politicians/HRC?" Warmth and competence ratings were separately averaged for women, female politicians, and Hillary Clinton (Warmth: women $\alpha_{\mathrm{St} 1}=.751, \alpha_{\mathrm{St} 2}=.798$, female politicians $\alpha_{\mathrm{St} 1}=.719$, $\alpha_{\mathrm{St} 2}=.720$, Hillary Clinton $\alpha_{\mathrm{St} 1}=.713, \alpha_{\mathrm{St} 2}=.789$; Competence: women $\alpha_{\mathrm{St} 1}=.761, \alpha_{\mathrm{St} 2}=.794$, female politicians $\alpha_{\mathrm{St} 1}=.823, \alpha_{\mathrm{St} 2}=.804$, Hillary Clinton $\alpha_{\mathrm{St} 1}=.805, \alpha_{\mathrm{St} 2}=.789$ ).

\section{Results}

We present the means, standard deviations, and ranges for Studies 1-3 in Table 1; correlations between all measures for Studies 1-3 are presented in Table 2. To examine whether the stereotypes associated with women and/or female politicians contributed to the impression of Hillary Clinton, first we predicted Hillary Clinton's warmth from women's warmth, female politicians' warmth, the context that Hillary Clinton was pictured in (no context $=0$ versus a family context $=1$; no context $=0$ versus a political context $=1$ ), and their interactions. Next, we predicted Hillary Clinton's competence from women's competence, female politicians' competence, the context that Hillary Clinton was pictured in, and their interactions. We present effects related to our key hypotheses for clarity, complete regression tables are presented in Table 3.

Predicting Hillary Clinton's warmth. Overall, the model significantly predicted Hillary Clinton's warmth (Study 1: $F(11,222)=9.66, p<.001, R^{2}=.324$; Study 2: $\left.F(11,393)=19.09, p<.001, R^{2}=.348\right)$. Consistent with the subtyping 
Table 2. Correlations between All Measures in Studies 1-3

\begin{tabular}{|c|c|c|c|c|c|c|c|}
\hline \multicolumn{8}{|c|}{ Study 1} \\
\hline & & 1 & 2 & 3 & 4 & 5 & 6 \\
\hline 1. & Women's perceived warmth & - & - & - & - & - & - \\
\hline 2. & Women's perceived competence & $.293^{* * * *}$ & - & - & - & - & - \\
\hline 3. & Female politicians' perceived warmth & $.315^{\text {*** }}$ & $.368^{* * *}$ & - & - & - & - \\
\hline 4. & Female politicians' perceived competence & $.218^{* *}$ & $.521^{* * *}$ & $.450^{* * * *}$ & - & - & - \\
\hline 5. & Hillary Clinton's perceived warmth & .012 & $.273^{* * * *}$ & $.458^{* * * *}$ & $.271^{* * * *}$ & - & - \\
\hline 6. & Hillary Clinton's perceived competence & $.146^{*}$ & $.340^{>* * *}$ & $.231^{* * * *}$ & $.484^{* * * *}$ & $.535^{* * *}$ & - \\
\hline
\end{tabular}

\begin{tabular}{|c|c|c|c|c|c|c|c|}
\hline \multicolumn{8}{|c|}{ Study 2} \\
\hline & & 1 & 2 & 3 & 4 & 5 & 6 \\
\hline 1. & Women's perceived warmth & - & - & - & - & - & - \\
\hline 2. & Women's perceived competence & $.375^{* * * *}$ & - & - & - & - & - \\
\hline 3. & Female politicians' perceived warmth & $.289^{* * * *}$ & $.275^{* * *}$ & - & - & - & - \\
\hline 4. & Female politicians' perceived competence & $.348^{* * * *}$ & $.597^{* * * *}$ & $.458^{* * * *}$ & - & - & - \\
\hline 5. & Hillary Clinton's perceived warmth & $.196^{* * *}$ & $.133^{* *}$ & $.578^{* * * *}$ & $.317^{* * *}$ & - & - \\
\hline 6. & Hillary Clinton's perceived competence & $.299^{* * * *}$ & $.142^{* *}$ & $.330^{* * * *}$ & $.515^{* * *}$ & $.536^{* * *}$ & - \\
\hline
\end{tabular}

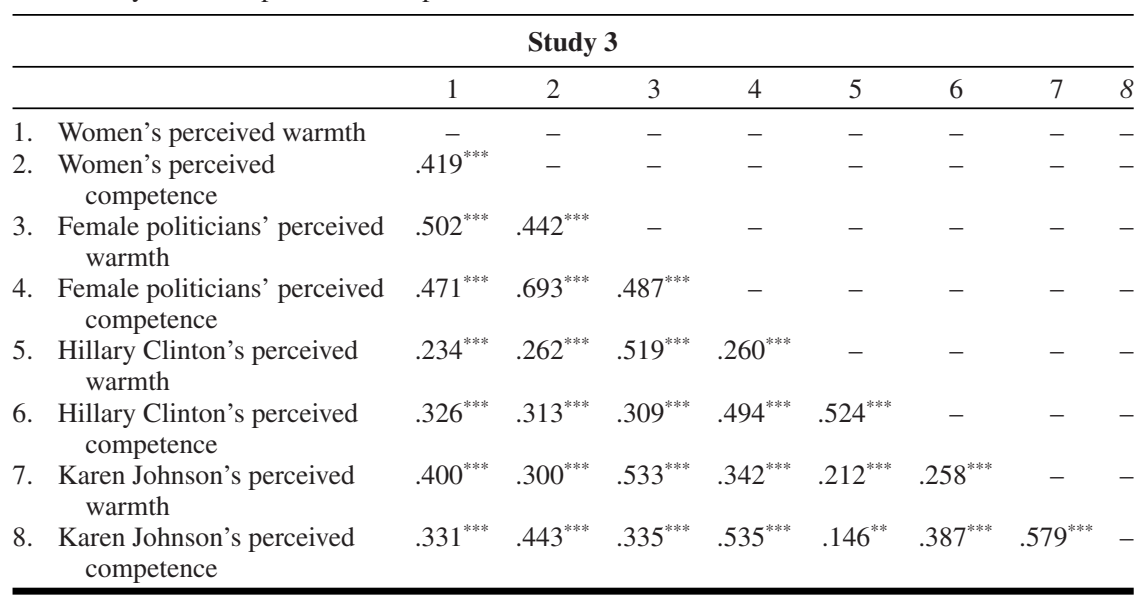

${ }^{*} p \leq .050 ;{ }^{* *} p<.01 ;{ }^{* * *} p<.001$.

hypothesis, to the extent that female politicians were perceived as warm, Hillary Clinton was also perceived as warm (Study 1: $b=0.542, \beta=0.502, t(11,222)=$ $4.48, p<.001$; Study 2: $b=0.577, \beta=0.469, t(11,393)=6.136, p<.001)$. Women's perceived warmth was not related to Hillary Clinton's perceived warmth (Study 1: $b=-0.198, \beta=-0.140, t(11,222)=-0.943, p=.347$; Study 2: $b=0.161, \beta=0.106, t(11,393)=1.41, p=.158)$. No support for either contextualization hypothesis occurred in Studies 1 and 2 , bs $<0.155, \beta s<0.079$, ps $>.050$. 
Table 3. Women's Perceived Warmth/Competence, Female Politicians' Perceived Warmth/Competence, Context, and Their Interactions Predicting Hillary Clinton's and Karen Johnson's Warmth/Competence

\begin{tabular}{|c|c|c|c|c|c|c|c|c|}
\hline \multirow[b]{3}{*}{ Predictor Variables } & \multicolumn{6}{|c|}{ Hillary Clinton's warmth } & \multirow{2}{*}{\multicolumn{2}{|c|}{$\begin{array}{c}\begin{array}{c}\text { Karen } \\
\text { Johnson's } \\
\text { warmth }\end{array} \\
\text { Study } 3 \\
\end{array}$}} \\
\hline & \multicolumn{2}{|c|}{ Study 1} & \multicolumn{2}{|c|}{ Study 2} & \multicolumn{2}{|c|}{ Study 3} & & \\
\hline & $b$ & $\beta$ & $b$ & $b$ & $\beta$ & $\beta$ & $\beta$ & $\beta$ \\
\hline Family versus no context & .105 & .077 & .113 & .067 & - & - & -.006 & -.004 \\
\hline Political versus no context & -.112 & -.083 & .113 & .061 & - & - & -.120 & -.089 \\
\hline $\begin{array}{l}\text { Women's perceived } \\
\text { warmth }\end{array}$ & -.198 & -.140 & .161 & .106 & -.048 & -.031 & $.324^{* * *}$ & .266 \\
\hline $\begin{array}{l}\text { Female politicians' } \\
\text { perceived warmth }\end{array}$ & $.542^{* * *}$ & $* .502$ & $.577^{* * * *}$ & .469 & $.605^{* * *}$ & .534 & $.345^{* * *}$ & .389 \\
\hline $\begin{array}{l}\text { Family } \times \text { Women's } \\
\text { perceived warmth }\end{array}$ & -.099 & -.042 & -.140 & -.059 & - & - & $-.244^{ \pm}$ & -.111 \\
\hline $\begin{array}{l}\text { Family } \times \text { Female } \\
\text { politicians' perceived } \\
\text { warmth }\end{array}$ & .120 & .066 & .155 & .079 & - & - & .041 & .025 \\
\hline $\begin{array}{c}\text { Political } \times \text { Women's } \\
\text { perceived warmth }\end{array}$ & -.053 & -.025 & -.126 & -.042 & - & - & -.100 & -.044 \\
\hline $\begin{array}{l}\text { Political } \times \text { Female } \\
\text { politicians' perceived } \\
\text { warmth }\end{array}$ & $-.310^{ \pm}$ & -.167 & .107 & .046 & - & - & .072 & .048 \\
\hline $\begin{array}{l}\text { Women's perceived } \\
\text { warmth } \times \text { Female } \\
\text { politicians' perceived } \\
\text { warmth }\end{array}$ & $1.093^{* *}$ & 0.516 & .085 & .049 & -.067 & -.054 & .090 & .065 \\
\hline $\begin{array}{l}\text { Family } \times \text { Women's } \\
\text { perceived warmth } \times \\
\text { Female politicians' } \\
\text { perceived warmth }\end{array}$ & $-1.158^{* *}$ & -.333 & .081 & .031 & - & - & .087 & .038 \\
\hline \multirow[t]{4}{*}{$\begin{array}{l}\text { Political } \times \text { Women's } \\
\text { perceived warmth } \times \\
\text { Female politicians' } \\
\text { perceived warmth }\end{array}$} & -.535 & -.184 & -.004 & -.001 & - & - & -.001 & .000 \\
\hline & \multicolumn{6}{|c|}{ Hillary Clinton's Competence } & \multirow{2}{*}{\multicolumn{2}{|c|}{$\begin{array}{c}\text { Karen } \\
\text { Johnson's } \\
\text { Competence }\end{array}$}} \\
\hline & \multicolumn{2}{|c|}{ Study 1} & \multicolumn{2}{|c|}{ Study 2} & \multicolumn{2}{|c|}{ Study 3} & & \\
\hline & $b$ & $\beta$ & $b$ & $b$ & $\beta$ & $\beta$ & $\beta$ & $\beta$ \\
\hline Family versus no context & .078 & .053 & -.016 & -.009 & - & - & .066 & .051 \\
\hline Political versus no context & -.025 & -.017 & .029 & .015 & - & - & $.200^{* *}$ & .154 \\
\hline $\begin{array}{l}\text { Women's perceived } \\
\text { competence }\end{array}$ & -.193 & -.175 & -.184 & -.140 & -.067 & -.055 & $.318^{* * *}$ & .365 \\
\hline $\begin{array}{l}\text { Female politicians' } \\
\text { perceived competence }\end{array}$ & $.676^{* * *}$ & .633 & $.667^{* * * *}$ & .574 & $.605^{* * *}$ & .528 & $.341^{* * *}$ & .418 \\
\hline $\begin{array}{l}\text { Family } \times \text { Women's } \\
\text { perceived competence }\end{array}$ & $.343^{ \pm}$ & .184 & $-.278^{ \pm}$ & -.137 & - & - & $-.429^{* * * *}$ & -.282 \\
\hline
\end{tabular}


Table 3. Continued

\begin{tabular}{|c|c|c|c|c|c|c|c|c|}
\hline \multirow[b]{3}{*}{ Predictor Variables } & \multicolumn{6}{|c|}{ Hillary Clinton's warmth } & \multirow{2}{*}{\multicolumn{2}{|c|}{$\begin{array}{c}\begin{array}{c}\text { Karen } \\
\text { Johnson's } \\
\text { warmth }\end{array} \\
\text { Study } 3\end{array}$}} \\
\hline & \multicolumn{2}{|c|}{ Study 1} & \multicolumn{2}{|c|}{ Study 2} & \multicolumn{2}{|c|}{ Study 3} & & \\
\hline & $b$ & $\beta$ & $b$ & $b$ & $\beta$ & $\beta$ & $\beta$ & $\beta$ \\
\hline $\begin{array}{l}\text { Family } \times \text { Female } \\
\text { politicians' perceived } \\
\text { competence }\end{array}$ & -.142 & -.074 & .221 & .119 & - & - & .116 & .082 \\
\hline $\begin{array}{l}\text { Political } \times \text { Women's } \\
\text { perceived competence }\end{array}$ & $.470^{*}$ & .257 & -.085 & -.033 & - & - & -.162 & -.108 \\
\hline $\begin{array}{l}\text { Political } \times \text { Female } \\
\text { politicians' perceived } \\
\text { competence }\end{array}$ & $-.418^{* *}$ & -.245 & .031 & .013 & - & - & -.041 & -.030 \\
\hline $\begin{array}{l}\text { Women's perceived } \\
\text { competence } \times \text { Female } \\
\text { politicians' perceived } \\
\text { competence }\end{array}$ & -.054 & -.043 & .011 & .007 & -.045 & -.034 & -.019 & -.020 \\
\hline $\begin{array}{l}\text { Family } \times \text { Women's } \\
\text { perceived competence } \\
\times \text { Female politicians' } \\
\text { perceived competence }\end{array}$ & .162 & .078 & .190 & .084 & - & - & $.234^{*}$ & .157 \\
\hline $\begin{array}{l}\text { Political } \times \text { Women's } \\
\text { perceived competence } \\
\times \text { Female politicians' } \\
\text { perceived competence }\end{array}$ & .095 & .043 & .024 & .009 & - & - & -.047 & -.030 \\
\hline
\end{tabular}

Note ${ }^{ \pm} p<.100,{ }^{*} p \leq .050,{ }^{* *} p \leq .010,{ }^{* * *} p \leq .001$. In Study 3 , the manipulated context involved Karen Johnson, not Hillary Clinton. Thus, contextual effects could not be examined for Hillary Clinton in Study 3.

Predicting Hillary Clinton's competence. Overall, the model significantly predicted Hillary Clinton's competence (Study 1: $F(11,222)=8.20, p<.001$, $R^{2}=.289$; Study 2: $\left.F(11,393)=17.047, p<.001, R^{2}=.323\right)$. Consistent with the subtyping hypothesis, to the extent that female politicians were perceived as competent, Hillary Clinton was also perceived as competent (Study 1: $b=0.646$, $\beta=0.633, t(11,222)=5.59, p<.001 ;$ Study $2: b=0.667, \beta=0.574, t(11,393)=$ $6.27, p<.001)$. As was the case with warmth stereotypes, women's perceived competence was not related to Hillary Clinton's perceived competence (Study 1: $b$ $=-0.193, \beta=-0.175, t(11,222)=-1.38, p=.170$; Study $2: b=-0.184, \beta=$ $-0.140, t(11,393)=-1.45, p=.147)$.

Partial support for the contextualization hypotheses arose, but the findings were inconsistent across Studies 1 and 2, making us hesitant to strongly interpret the results. In Study 1, a significant interaction emerged between Hillary Clinton in a political context versus no context and women's competence $(b=0.470, \beta=$ $0.257, t(11,222)=2.55, p=.011)$. To the extent that women were perceived as 
competent, Hillary Clinton was also perceived as competent when pictured in a political context $(b=0.277, \beta=0.277, p=.018$ ), but no relationship between women's perceived competence and Hillary Clinton's competence emerged in no context $(b=-0.193, \beta=-0.160, p=.190)$. Furthermore, in Study 1 , a significant interaction emerged between Hillary Clinton in a political context versus no context and female politicians' competence $(b=-0.428, \beta=-0.245$, $t(11,222)=-2.66, p=.008)$. To the extent that female politicians were perceived as competent, counter to our hypotheses, Hillary Clinton was perceived as more competent, but this effect emerged stronger in no context $(b=0.646, \beta=0.647$, $p<.001)$ as opposed to a political context $(b=0.227, \beta=0.244, p=.029)$. No other significant contextualization effects emerged for warmth in Studies 1 or 2 ( $b s<0.221, \beta s<0.119$, ps $>.117$ ). Thus, we did not find consistent support for either contextualization hypothesis; the pattern of results dramatically differed between Studies 1 and 2 .

\section{Discussion}

Across Studies 1 and 2 and consistent with Schneider and Bos (2014), evidence emerged in support of the subtyping hypothesis. Hillary Clinton was perceived as warm and competent to the extent that female politicians were also perceived as warm and competent. No support for the subgrouping hypothesis emerged; Hillary Clinton's perceived warmth and competence was unrelated to women's perceived warmth and competence. Furthermore, no consistent evidence for the contextualization hypotheses emerged across Studies 1 and 2. In Study 1, but not Study 2, when participants were provided with a political context, support for the subtyping contextualization hypothesis emerged with Hillary Clinton's perceived competence being related to female politicians' perceived competence. Furthermore, contrary to our predictions, Hillary Clinton's perceived competence was related to female politicians' perceived competence, but this effect was stronger in no context than a political context.

\section{Study 3}

One weakness of Studies 1 and 2 was that because of Hillary Clinton's long history in politics, the vast majority of participants may have already formed an impression of her. Therefore, their categorization of her may have been less influenced by contextual cues. However, when little is known about a female political candidate, beliefs about the roles of men and women within society play an important role in candidate evaluation (Alexander \& Andersen, 1993). Because these gender role beliefs are associated with the development of stereotypes about men and women (i.e., Eagly et al., 2000), perhaps when little information is known about a female political candidate, she will be subgrouped rather than subtyped 
because participants will use the stereotypes associated with her group memberships (women, female politicians) to categorize her. In Study 3, we addressed these issues by exposing participants to a novel female political candidate named Karen Johnson in a context with cues related to politics, family, or neither. We examined whether participants subtyped, subgrouped, or contextualized Karen Johnson and whether they subtyped or subgrouped Hillary Clinton.

Another benefit of Study 3's design is that it allows us to address possible concerns about reverse causation in Studies 1 and 2. It is possible that initially viewing an image of Hillary Clinton influenced how participants responded to questions about women and female politicians. Thus, any relationships between the traits applied to Hillary Clinton and the stereotypes of those two categories might depend on first seeing an image of Hillary Clinton. In Study 3, however, participants did not view an image of Hillary Clinton at any point and always answered questions about Hillary Clinton only after answering all questions about women, female politicians, and Karen Johnson. Therefore, reverse causation cannot be a possible explanation for the pattern of results found in regards to Hillary Clinton in Study 3.

\section{Method}

Participants. Three hundred eighty-four participants $(55.2 \%$ women, $0.5 \%$ did not identify a gender; $77.34 \%$ White, $2.34 \%$ Latino, $9.38 \%$ Black, $3.65 \%$ Asian, $1.82 \%$ other, $5.47 \%$ did not identify; ages $18-73$, median age $=34.5 ; 46.4 \%$ liberal, 24.2\% moderate, 28.8\% conservative) were recruited using Amazon's Mechanical TURK in exchange for payment.

Procedure. First, participants viewed a picture of Karen Johnson (context manipulation) and then completed ratings of the warmth and competence of the following groups/individuals in a random order: women, female politicians, and Karen Johnson. Lastly, participants completed ratings of the warmth and competence of Hillary Clinton. Demographic information was also collected.

Context manipulation. Participants were told that we were interested in their "thoughts about candidates running for political office" and to "take some time and look at the candidate, Karen Johnson, pictured below." Next, participants were randomly assigned to view a picture of a novel fictional female politician, Karen Johnson, either in no context, a family context, or a political context. The name Karen was selected because it was associated with moderate competence and attractiveness (Kasof, 1993; see Appendix B).

Warmth and competence ratings. Next, participants rated women's, female politicians', Karen Johnson's, and Hillary Clinton's warmth (eight items per 
group/individual rated) and competence (eight items per group/individual rated; Fiske, Cuddy, Glick, \& Xu, 2002) using the same 5-point scales used in Studies 1 and 2. Warmth and competence ratings were separately averaged for women, female politicians, Karen Johnson, and Hillary Clinton (Warmth: women $\alpha=$ .773 , female politicians $\alpha=.794$, Karen Johnson $\alpha=.852$, Hillary Clinton $\alpha=$ .773; Competence: women $\alpha=.854$, female politicians $\alpha=.826$, Karen Johnson $\alpha=.841$, Hillary Clinton $\alpha=.803$ ).

\section{Results}

Similar to Studies 1 and 2, we examined the extent to which the stereotypes associated with women and female politicians contributed to the traits associated with Hillary Clinton and Karen Johnson. We predicted Karen Johnson's warmth from women's warmth, female politicians' warmth, the context that Karen Johnson was pictured (no context $=0$ vs. family context $=1$; no context $=0$ vs. political context $=1$ ), and their interactions. To calculate Hillary Clinton's warmth we repeated these analyses without accounting for context as we only manipulated Karen Johnson's context. Next, we predicted Karen Johnson's competence from women's competence, female politicians' competence, the context that Karen Johnson was pictured, and their interactions. To calculate Hillary Clinton's competence we repeated these analyses without accounting for context. We present effects related to our key hypotheses for clarity, complete regression tables are presented in Table 3.

Predicting Karen Johnson's warmth. The overall model significantly predicted Karen Johnson's warmth, $F(11,369)=16.44, p<.001, R^{2}=.329$. Consistent with the subgrouping hypothesis and participants using their stereotypes of women and female politicians to categorize a novel female politician, to the extent that both female politicians and women were perceived as warm, Karen Johnson was also perceived as warm (female politicians: $b=0.345, \beta=0.389, t(11,369)=$ $4.59, p<.001$; women: $b=0.324, \beta=0.266, t(11,369)=3.40, p=.001)$. No support for either contextualization hypothesis emerged $(b s<0.072, \beta s<0.108$, ps $>.088$ ).

Predicting Hillary Clinton's warmth. The overall model significantly predicted Hillary Clinton's warmth, $F(11,369)=47.108, p<.001, R^{2}=.273$. Consistent with the findings of Studies 1 and 2 and the subtyping hypothesis, to the extent that female politicians were perceived as warm, Hillary Clinton was also perceived as warm, $b=0.605, \beta=0.534, t(11,369)=10.51, p<.001$. However, 
women's perceived warmth was not related to Hillary Clinton's perceived warmth, $b=-0.048, \beta=-0.031, t(11,369)=-0.61, p=.542{ }^{1}$

Predicting Karen Johnson's competence. The overall model significantly predicted Karen Johnson's competence, $F(11,369)=19.11, p<.001, R^{2}=.363$. Consistent with the subgrouping hypothesis and participants using their stereotypes of women and female politicians to categorize a novel female politician, to the extent that both female politicians and women were perceived as competent, Karen Johnson was also perceived as competent (female politicians: $b=0.341$, $\beta=0.418, t(11,369)=4.01, p<.001$; women: $b=0.318, \beta=0.365, t(11,369)=$ $3.701, p<.001)$.

Evidence inconsistent with the subgrouping contextualization effect also occurred. An interaction emerged between Karen Johnson in a family versus no context and women's competence, $b=-0.429, \beta=-0.282, t(11,369)=-3.58$, $p<.001$. In no context, to the extent that women were perceived as competent, Karen Johnson was perceived as more competent, $b=0.318, \beta=0.350, p<.001$, but when Karen Johnson was pictured in a family context, women's perceived competence was not related to Karen Johnson's perceived competence, $b=-0.111$, $\beta=-0.133, p=.194$. No additional contextualization effects emerged, $b s<$ $0.116, \beta s<0.082$, $p s>.200$. We again did not find consistent and substantial support for either contextualization hypothesis, making us hesitant to strongly interpret these effects.

Predicting Hillary Clinton's competence. The overall model significantly predicted Hillary Clinton's competence, $F(11,369)=41.263, p<.001, R^{2}=$ .247 . Consistent with Studies 1 and 2 and the subtyping hypothesis, to the extent that female politicians were perceived as competent, Hillary Clinton was also perceived as competent, $b=0.605, \beta=0.528, t(11,369)=8.48, p<.001$. Again, women's perceived competence was not related to Hillary Clinton's competence, $b=-0.067, \beta=-0.055, t(11,369)=-0.88, p=.378 .^{2}$

\section{Discussion}

Consistent with Studies 1 and 2 and Schneider and Bos (2014), when participants evaluated Hillary Clinton, support for the subtyping hypothesis emerged.

\footnotetext{
${ }^{1}$ The pattern of results remained when the context manipulation and its interactions were accounted for in the analyses. To the extent that female politicians were seen as warm, Hillary Clinton was also perceived as warm, $p<.05$. Again women's perceived warmth was not associated with Hillary Clinton's perceived warmth, $p>.10$.

${ }^{2}$ The pattern of results remained when the context manipulation and its interactions were accounted for in the analyses. To the extent that female politicians were seen as competent, Hillary Clinton was also perceived as competent, $p<.05$. Again women's perceived competence was not associated with Hillary Clinton's perceived competence, $p>.10$.
} 
Hillary Clinton was rated as warm and competent to the extent that female politicians were rated as warm and competent. Because Hillary Clinton has a long history in politics, many participants likely had a well-formed impression of her within the political domain, leading to Hillary Clinton being subtyped as a politician. As anticipated, when participants evaluated a novel female political candidate named Karen Johnson, support for the subgrouping hypothesis emerged. Karen Johnson was rated as warm and competent to the extent that both female politicians and women were rated as warm and competent, which is consistent with the idea that participants' lack of knowledge about Karen Johnson caused them to rely on the stereotypes associated with her category memberships (both a woman and a female politician) for categorization. Consistent with Studies 1 and 2, no evidence for either contextualization hypothesis emerged. Inconsistent with the subgrouping contextualization hypothesis, in a family context, Karen Johnson's competence was not predicted by women's perceived competence.

\section{General Discussion}

Using regression analyses to directly investigate categorization processes, the current findings provide evidence for both the subtyping (Studies 1-3) and subgrouping (Study 3) of individual female politicians. Across student (Study 1) and MTurk (Studies 2 and 3) samples, the warmth and competence traits applied to Hillary Clinton, a well-known political candidate, were solely predicted by the warmth and competence stereotypes of female politicians and not the warmth and competence stereotypes of women (subtyping). In contrast, Study 3 provides evidence that the warmth and competence traits applied to a novel fictional female politician, previously unknown to participants, were predicted by the warmth and competence stereotypes of both female politicians and women (subgrouping).

The latter results are notable because if we had solely examined the outcomes of categorization processes by examining the content of stereotypes associated with both women and female politicians, it might have led to the conclusion that a novel female politician was subtyped similarly to Hillary Clinton. Though this conclusion would have been consistent with the findings of Schneider and Bos (2014), our strategy of testing the extent to which group stereotypes predicted the traits associated with individuals provided additional insight into how specific female politicians are categorized.

Notably, we did not find consistent evidence that the categorization of female politicians was moderated by context for both, the well-known, Hillary Clinton and a novel female politician previously unknown to participants. In fact, only in Study 1, but not in Studies 2 and 3, did support for the subtyping contextualization hypothesis emerge. When Hillary Clinton was pictured in a political context, female politicians' perceived competence predicted Hillary Clinton's perceived competence. The lack of consistent findings related to context across Studies 1-3 
suggest that context is not a consistent or strong moderator of categorization processes.

By understanding how well-known and novel female politicians are categorized, we can develop better anti-bias strategies in the future. Evidence that a well-known female politician is categorized as only a female politician (subtyped) whereas a novel female politician is categorized as both a woman and a female politician (subgrouped) has important implications for strategies to reduce bias. Since subtyping means that an individual female politician is essentially kicked out of the broader social group of women, subtyping serves to maintain the stereotypes associated with the broader social category by removing inconsistent group members (Richards \& Hewstone, 2001). However, subgrouping means that an individual female politician is now included in a more diverse representation of the broader social group of women that includes both individuals that fit and do not fit the stereotypes associated with women, leading to more stereotype differentiation (Richards \& Hewstone, 2001).

To develop effective interventions that target the stereotypes applied to individuals, it is necessary to know how those individuals are categorized. For instance, because well-known female politicians are subtyped, the most effective interventions to change the traits applied to them as individuals should only target stereotyping of female politicians at the group level. However, because we found in Study 3 that novel female politicians are subgrouped, the most effective interventions to change the traits applied to them as individuals should target both the stereotyping of women and the stereotyping of female politicians at the group level. Put another way, interventions that change stereotyping of female politicians at the group level should influence the traits applied to well-known female politicians like Hillary Clinton but may have little influence on the traits applied to novel female politicians.

Thus, as Phills et al. (2017) argue, understanding how an individual is categorized is critical to predicting whether interventions that target bias at the group level (e.g., Kawakami, Phills, Steele, \& Dovidio, 2007; Phills, Kawakami, Krusemark, \& Nyguyen, 2017; Phills, Kawakami, Tabi, Nadolny, \& Inzlicht, 2011) will influence the traits associated with that individual. For example, using an intervention that reduces gender bias in hiring decisions by instructing participants to repeatedly associate counterstereotypes with women (Kawakami, Dovidio, \& Van Kamp, 2005; 2007) should also influence the traits applied to novel female politicians (because they are subgrouped) but should not influence the traits associated with well-known female politicians (because they are subtyped). To change the traits applied to a well-known female politician it may be necessary to instruct participants to repeatedly associate counterstereotypes with female politicians rather than women. Within a political context, if voters were repeatedly encouraged to think about how female politicians are associated with counterstereotypic traits or female politicians were repeatedly paired with counterstereotypic traits, 
the traits applied to well-known female politicians might change over time. Thus, if the goal is to change the traits applied to all female politicians, the best strategy may be to target stereotyping of female politicians rather than women because the traits of both well-known and novel female politicians are related to stereotyping of female politicians.

An alternative strategy to reduce bias against both well-known and novel female politicians would be to change how they are categorized rather than the stereotypes associated with the categories they belong to. For example, training people to categorize female politicians as leaders might be effective at changing the traits applied to all female politicians. In an experimental setting, participants could be repeatedly presented with an image of a female politician on a computer screen and instructed to drag that image into an onscreen circle representing the group "Leaders" and away from an onscreen circle representing the group "Followers." Alternatively, political campaigns could repeatedly present voters with imagery pairing a female politician with words and concepts related to being a leader. Learning to categorize female politicians as "Leaders" in this way should cause the stereotypes associated with leaders to be applied to individual female politicians.

Effective anti-bias strategies would ultimately increase women's representation in leadership positions and help the U.S. to achieve a government that is reflective of its population. Additionally, because women are more likely than men to endorse social policies that are compassionate, moral, and promote the equal rights of women, gays, and lesbians (Eagly, Diekman, Johannesen-Schmidt, \& Koenig, 2004), and people prefer voting for politicians who endorse gender-consistent political policies (Eagly, Diekman, Schneider, \& Kulesa, 2003), increasing the number of women in politics will likely increase the prevalence of sociopolitical policies that women value as well as increase the percentage of women who vote in general elections.

Future research should also examine whether other well-known female politicians are categorized in the same way as Hillary Clinton (subtyped) or if they are categorized more similarly to the fictional Karen Johnson (subgrouped). The fact that Hillary Clinton is well-known is just one possible reason why she is subtyped and excluded from the category women in participants' minds. Another possibility is that she is subtyped because she is so strongly associated with the attribute "competence" and women are rated as less competent than men. If this is true, then a well-known but less competent female politician (i.e., Sarah Palin) might also be subgrouped like Karen Johnson rather than subtyped like Hillary Clinton.

Furthermore, it is important to consider how party affiliation may influence the categorization of female politicians because previous research has found that impressions of female politicians are related to perceived party affiliation (King \& Matland, 2003; Huddy \& Capelos, 2002; Sanbonmatsu \& Dolan, 2009). For 
example, Republican voters had more negative impressions of a Republican female politician than Democratic or Independent voters (King \& Matland, 2003). Moreover, stereotypes about political parties constrain the impact of gender stereotypes on political candidates (Hayes, 2011), and feminine stereotypes overlap with partisan stereotypes (Bauer, 2017). Thus, stereotyping of female politicians may depend not only on whether they are categorized as women and/or female politicians but also on whether they are categorized as a Republican or Democrat. Future research should use our regression analysis strategy to assess the extent to which the stereotypes of political groups predict the traits associated with specific female politicians.

In conclusion, to gain a fuller understanding of individuals who can be categorized into multiple groups like female politicians, future research should measure categorization directly as well as stereotype overlap between groups. To develop effective bias reduction strategies, it is especially important to understand whether a person has been subgrouped or subtyped. If we can understand and help alleviate bias against female politicians, we will be better able to address the underrepresentation of women within politics and promote a government that is truly representative of the people.

\section{References}

Abelson, R. P., Kinder, D. R., Peters, M. D., \& Fiske, S. T. (1982). Affective and semantic components in political person perception. Journal of Personality and Social Psychology, 42, 619-630. https://doi.org/10.1037/0022-3514.42.4.619

Alexander, D., \& Andersen, K. (1993). Gender as a factor in the attribution of leadership traits. Political Research Quarterly, 46(3), 527-545. https://doi.org/10.1177/106591299304600305

Allport, G. W. (1954). The nature of prejudice. Reading, MA: Addison-Wesley.

Bauer, N. M. (2017). Untangling the relationship between partisanship, gender stereotypes, and support for female candidates. Journal of Women, Politics \& Policy. https://doi.org/10.1080/ 1554477X.2016.1268875

Cuddy, A. J., Fiske, S. T., \& Glick, P. (2008). Warmth and competence as universal dimensions of social perception: The stereotype content model and the BIAS map. Advances in Experimental Social Psychology, 40, 61-149. https://doi.org/10.1016/S0065-2601(07)00002-0

Dasgupta, N., \& Asgari, S. (2004). Seeing is believing: Exposure to counterstereotypic women leaders and its effect on the malleability of automatic gender stereotyping. Journal of Experimental Social Psychology, 40, 642-658. https://doi.org/10.1016/j.jesp.2004.02.003

De Houwer, J., \& Moors, A. (2015). Levels of analysis in social psychology. In B. Gawronski \& G. Bodenhausen (Eds.), Theory and Explanation in Social Psychology (pp. 24-40). New York: Guilford.

Dolan, K. (2010). The impact of gender stereotyped evaluations on support for women candidates. Political Behavior, 32(1), 69-88. https://doi.org/10.1007/s11109-009-9090-4

Dovidio, J. F., Brigham, J. C., Johnson, B. T., \& Gaertner, S. L. (1996). Stereotyping, prejudice and discrimination: Another look. In C. N. Macrae, C. Stangor, \& M. Hewstone (Eds.), Stereotypes and Stereotyping (pp. 276-319). New York: Guilford.

Eagly, A. H., \& Diekman, A. B. (2006). Examining gender gaps in sociopolitical attitudes: It's not Mars and Venus. Feminism \& Psychology, 16, 26-34. https://doi.org/10.1177/0959-353506060817

Eagly, A. H., Diekman, A. B., Johannesen-Schmidt, M. C., \& Koenig, A. M. (2004). Gender gaps in sociopolitical attitudes: A social psychological analysis. Journal of Personality and Social Psychology, 87, 796-816. https://doi.org/10.1037/0022-3514.87.6.796 
Eagly, A. H., Diekman, A. B., Schneider, M. C., \& Kulesa, P. (2003). Experimental tests of an attitudinal theory of the gender gap in voting. Personality and Social Psychology Bulletin, 29, 1245-1258. https://doi.org/10.1177/0146167203255765

Eagly, A. H., \& Karau, S. J. (2002). Role congruity theory of prejudice toward female leaders. Psychological Review, 109(3), 573-598. https://doi.org/10.1037/0033-295X.109.3.573

Eagly, A. H., Wood, W., \& Diekman, A. B. (2000). Social role theory of sex differences and similarities: A current appraisal. In T. Eckes \& H. M. Trautner (Eds.), The Developmental Social Psychology of Gender (pp. 123-174). New York: Psychology Press.

Fiske, S., Cuddy, A., Glick, P., \& Xu, J. (2002). A model of (often mixed) stereotype content: Competence and warmth respectively follow from perceived status and competition. Journal of Personality and Social Psychology, 82(6), 878-902. https://doi.org/10.1037/0022-3514.82.6.878

Fiske, S. T., \& Neuberg, S. L. (1990). A continuum of impression formation, from category-based to individuating processes: Influences of information and motivation on attention and interpretation. Advances in Experimental Social Psychology, 23, 1-74. https://doi.org/10.1016/S00652601(08)60317-2

Gawronski, B., Rydell, R. J., Vervliet, B., \& De Houwer, J. (2010). Generalization versus contextualization in automatic evaluation. Journal of Experimental Psychology: General, 139(4), 683-701. https://doi.org/10.1037/a0020315

Hayes, D. (2011). When gender and party collide: Stereotyping in candidate trait attribution. Politics \& Gender, 7(2), 133-165. https://doi.org/10.1017/S1743923X11000055

Hewstone, M., Macrae, C. N., Griffiths, R., Milne, A. B., \& Brown, R. (1994). Cognitive models of stereotype change: Measurement, development, and consequences of subtyping. Journal of Experimental Social Psychology, 30, 505-526. https://doi.org/10.1006/jesp.1994.1024

Huang, L. M., Sacchi, D. L. M., \& Sherman, J. W. (2017). On the formation of contextbased person impressions. Journal of Experimental Social Psychology, 68, 146-156. https://doi.org/10.1016/j.jesp.2016.06011

Huddy, L., \& Terkildsen, N. (1993). Gender stereotypes and the perception of male and female candidates. American Journal of Political Science, 37(1), 119-147. https://doi.org/10.2307/2111526

Huddy, L., \& Capelos, T. (2002). Gender stereotyping and candidate evaluation. In V. Ottati, S. Tindale, J. Edwards, F. Bryant, L. Health, D. O’Connell, Y. Suarez-Balzacar, E. J. Posavac (Eds.), The Social Psychology of Politics (pp. 29-53). New York: Springer.

Johnston, L., \& Hewstone, M. (1992). Cognitive models of stereotype change: Subtyping and the perceived typicality of disconfirming group members. Journal of Experimental Social Psychology, 28, 360-386. https://doi.org/10.1016/0022-1031(92)90051-K

Kasof, J. (1993). Sex bias in the naming of stimulus persons. Psychological Bulletin, 113(1), 140-163. https://doi.org/10.1037/0033-2909.113.1.140

Kawakami, K., Dovidio, J. F., \& Van Kamp, S. (2005). Kicking the habit: Effects of nonstereotypic association training and correction processes on hiring decisions. Journal of Experimental Social Psychology, 41(1), 68-75. https://doi.org/10.1016/j.jesp.2004.05.004

Kawakami, K., Dovidio, J. F., \& Van Kamp, S. (2007). The impact of counterstereotypic training and related correction processes on the application of stereotypes. Group Processes \& Intergroup Relations, 10(2), 139-156. https://doi.org/10.1177/1368430207074725

Kawakami, K., Phills, C. E., Steele, J. R., \& Dovidio, J. F. (2007). (Close) distance makes the heart grow fonder: Improving implicit racial attitudes and interracial interactions through approach behaviors. Journal of Personality and Social Psychology, 92(6), 957-71. http://doi.org/10.1037/00223514.92.6.957

King, D. C., \& Matland, R. E. (2003). Sex and the grand old party: An experimental investigation of the effect of candidate sex on support for a Republican candidate. American Politics Research, 31(6), 595-612. https://doi.org/10.1177/1532673X03255286

Koenig, A. M., Eagly, A. H., Mitchell, A. A., \& Ristikari, T. (2011). Are leader stereotypes masculine? A meta-analysis of three research paradigms. Psychological Bulletin, 137(4), 616-642. https://doi.org/10.1037/a0023557

Kunda, Z., \& Oleson, K. C. (1995). Maintaining stereotypes in the face of disconfirmation: Constructing grounds for subtyping deviants. Journal of Personality and Social Psychology, 68, 565-579. https://doi.org/10.1037/0022-3514.68.4.565 
Maurer, K. L., Park, B., \& Rothbart, M. (1995). Subtyping versus subgrouping processes in stereotype representation. Journal of Personality and Social Psychology, 69, 812-824. https://doi.org/10.1037/0022-3514.69.5.812

Park, B., \& Judd, C. M. (1990). Measures and models of perceived group variability. Journal of Personality and Social Psychology, 59, 173-191. https://doi.org/10.1037/0022-3514.59.2.173

Park, B., Ryan, C. S., \& Judd, C. M. (1992). Role of meaningful subgroups in explaining differences in perceived variability for in-groups and out-groups. Journal of Personality and Social Psychology, 63, 553-567. https://doi.org/10.1037/0022-3514.63.4.553

Phills, C. E., Kawakami, K., Krusemark, D., \& Nguyen, J. (2017). Does reducing prejudice increase outgroup identification? The downstream consequences of associating positive concepts with racial categories. Social Psychological and Personality Science. https://doi.org/10.1177/1948550617732817

Phills, C. E., Kawakami, K., Tabi, E., Nadolny, D., \& Inzlicht, M. (2011). Mind the gap: Increasing associations between the self and blacks with approach behaviors. Journal of Personality and Social Psychology, 100(2), 197-210. http://doi.org/10.1037/a0022159

Phills, C. E., Williams, A., Wolff, J. M., Smith, A., Arnold, R., Felegy, K., \& Kuenzig, M. E. (2017). Intersecting race and gender stereotypes: Implications for group-level attitudes. Group Processes \& Intergroup Relations. https://doi.org/10.1177/1368430217706742

Richards, Z., \& Hewstone, M. (2001). Subtyping and subgrouping: Processes for the prevention and promotion of stereotype change. Personality and Social Psychology Review, 5, 52-73. https://doi.org/10.1207/S15327957PSPR0501_4

Ryan, R. M., \& Deci, E. L. (2000). Self-determination theory and the facilitation of intrinsic motivation, social development, and well-being. American Psychologist, 55(1), 68-78. https://doi.org/10.1037/0003-066X.55.1.68

Sanbonmatsu, K. \& Dolan, K. (2009). Do gender stereotypes transcend party? Political Research Quarterly, 62(3), 69-88. https://doi.org/10.1007/s11109-009-9090-4

Schneider, M. C., \& Bos, A. L. (2011). An exploration of the content of stereotypes of black politicians. Political Psychology, 32(2), 205-233. https://doi.org/10.1111/j.1467-9221.2010.00809.x

Schneider, M. C., \& Bos, A. L. (2014). Measuring stereotypes of female politicians. Political Psychology, 35(2), 245-266. https://doi.org/10.1111/pops.12040

Stangor, C., Lynch, L., Duan, C., \& Glass, B. (1992). Categorization of individuals on the basis of multiple social features. Journal of Personality and Social Psychology, 62, 207-218. https://doi.org/10.1037/0022-3514.62.2.207

Tajfel, H. (1981). Human groups and social categories. Cambridge, England: Cambridge University Press.

Wojciszke, B., \& Klusek, B. (1996). Moral and competence-related traits in political perception. Polish Psychological Bulletin, 27, 319-324.

\section{Appendix A: The Context Manipulation for Hillary Clinton (No Context, Political Context, Or Family Context)-Studies 1 and 2}

- No context (modified from http://www3.pictures.gi.zimbio.com/Hillary+ Chelsea+Clinton+Host+Fundraiser+Washington+Q-Txqv_pet6x.jpg)

- Political context (modified from https://thecaucus.blogs.nytimes.com/ 2008/03/26/clinton-women-take-the-stage-in-dc/?_r=2)

- Family context (modified from http://www3.pictures.gi.zimbio.com/ Hillary+Chelsea+Clinton+Host+Fundraiser+Washington+QTxqv_pet6x.jpg) 


\section{Appendix B: The Context Manipulation for Karen Johnson (No Context, Political Context, Or Family Context)-Study 3}

- No context (http://www.gettyimages.com/detail/photo/caucasian-business woman-speaking-at-podium-royalty-free-image/152838576)

- Political context (http://www.gettyimages.com/detail/photo/female-politi cian-making-speech-at-podium-royalty-free-image/142021221)

- Family context (http://www.gettyimages.com/detail/photo/female-politician-making-speech-at-podium-royalty-free-image/142018768)

ELIZABETH R. BROWN is an Assistant Professor of Psychology at the University of North Florida.

CURTIS E. PHILLS is an Assistant Professor of Psychology at the University of North Florida.

DOMINIC G. MERCURIO IV recently received his Master's degree in Psychological Science from the University of North Florida.

MATTHEW OLAH is working on his Master's degree in Psychological Science at the University of North Florida and anticipates graduating in spring 2018.

CANDICE J. VEILLEUX is working on her Master's degree in Psychological Science at the University of North Florida and anticipates graduating in summer 2018. 